\title{
GIULIANO VIGINI, Honoré de Balzac, Alexandre Dumase Victor Hugo nelle edizioni milanesi dal 1860 al 1940
}

\section{Marco Stupazzoni}

\section{(2) OpenEdition}

\section{Journals}

\section{Edizione digitale}

URL: https://journals.openedition.org/studifrancesi/22896

DOI: 10.4000/studifrancesi.22896

ISSN: 2427-5856

\section{Editore}

Rosenberg \& Sellier

\section{Edizione cartacea}

Data di pubblicazione: 1 avril 2020

Paginazione: 195

ISSN: 0039-2944

\section{Notizia bibliografica digitale}

Marco Stupazzoni, «GIULIANo VIGINI, Honoré de Balzac, Alexandre Dumas e Victor Hugo nelle edizioni milanesi dal 1860 al 1940», Studi Francesi [Online], 190 (LXIV | I) | 2020, online dal 01 mai 2020, consultato il 02 août 2021. URL: http://journals.openedition.org/studifrancesi/22896 ; DOI: https://doi.org/10.4000/ studifrancesi.22896

Questo documento è stato generato automaticamente il 2 août 2021

\section{cc) (i) (2)}

Studi Francesi è distribuita con Licenza Creative Commons Attribuzione - Non commerciale - Non opere derivate 4.0 Internazionale. 


\title{
GIULIANO VIGINI, Honoré de Balzac, Alexandre Dumas e Victor Hugo nelle edizioni milanesi dal 1860 al 1940
}

\author{
Marco Stupazzoni
}

\section{NOTIZIA}

GIULIANO VIGINI, Honoré de Balzac, Alexandre Dumas e Victor Hugo nelle edizioni milanesi dal 1860 al 1940, in Editori a Milano. Una storia illustrata dal 1860 al 1940, Milano, Editrice Bibliografica, 2018, «I saggi», pp. 105-155; su Balzac, pp. 107-118.

1 Come Appendice a questo utile e interessante studio sulla storia editoriale di Milano dall'Unità d'Italia agli anni Trenta-Quaranta del Novecento, Giuliano Vigini presenta il repertorio delle traduzioni italiane delle opere di quegli autori francesi (Balzac, Dumas, Hugo) che vantano, nel periodo considerato, il maggior numero di titoli pubblicati da editori milanesi. In questa rassegna, le opere sono disposte in ordine alfabetico e, nel caso di più edizioni dello stesso titolo, dalla più antica alla più recente con l'esclusione delle traduzioni non in edizione autonoma, delle ristampe e degli adattamenti o delle riduzioni ad uso scolastico. Attraverso la massiccia presenza di questi testi nei cataloghi non solo delle grandi case editrici (Sonzogno o Treves, soprattutto per quel che riguarda il secondo Ottocento), ma anche dei piccoli editori, risulta evidente, osserva Vigini, che «la letteratura francese non è rimasta nella cultura italiana una stagione della giovinezza evocata con rimpianto negli anni della maturità, ma una presenza rinnovatrice che ha alimentato la tensione ideale di molte generazioni» (p. 106). 